\title{
Prenatal influences on susceptibility to diet-induced obesity are mediated by altered neuroendocrine gene expression
}

\author{
Bettina A Ikenasio-Thorpe, Bernhard H Breier, Mark H Vickers and Mhoyra Fraser \\ Liggins Institute and the National Research Centre for Growth and Development, University of Auckland, Auckland, New Zealand \\ (Requests for offprints should be addressed to M Fraser who is now at Liggins Institute, University of Auckland, Private Bag 92019, Auckland, New Zealand; \\ Email: m.fraser@auckland.ac.nz)
}

\begin{abstract}
The escalating rates of obesity and type 2 diabetes have reached pandemic proportions. It has been proposed that the risk of developing metabolic disorders in adult life is influenced by environmental factors, which operate during the early periods of development. We have previously shown that an interaction between the prenatal and the postnatal dietary environment amplifies the propensity towards dietinduced obesity, although the mechanisms are unclear. In the present study, we investigated the interaction between prenatal undernutrition and postnatal high-fat nutrition on key genes of the hypothalamic appetite regulatory network. Pregnant Wistar rats were fed a standard chow diet either ad libitum (AD) or at $30 \%$ of $\mathrm{AD}$ intake throughout gestation (UN). From weaning, female AD and UN offspring were fed either a standard chow (ADC $n=8, \mathrm{UNC} n=8$ ) or a high-fat $\operatorname{diet}(45 \% \mathrm{kcal}$ as fat; $\mathrm{ADHF} n=8$, UNHF $n=8)$ ad libitum for the remainder of the study. At 24 weeks of age, body composition was assessed by dual energy X-ray
\end{abstract}

absorptiometry analysis and total RNA was extracted from whole rat hypothalami. Real-time PCR was performed to characterise pro-opiomelanocortin (POMC), neuropeptide $\mathrm{Y}(\mathrm{NPY})$, agouti-related protein (AgRP) and OBRb gene expression at the mRNA level. Our results demonstrate that the amplification of postnatal obesity develops as a consequence of an interaction between prenatal undernutrition and postnatal high-fat nutrition. This phenotype also shows significant alterations in POMC, NPY, AgRP and $\mathrm{OBRb}$ gene expression together with elevations in circulating levels of both plasma leptin and insulin. These findings are consistent with the predictive adaptive response hypothesis that neuroendocrine development during fetal life may be based on predictions about postnatal environmental conditions. Increased susceptibility to diet-induced obesity develops if a mismatch between the anticipated and the actual conditions are encountered.

Journal of Endocrinology (2007) 193, 31-37

\section{Introduction}

Obesity, a key risk factor for cardiovascular disease and type 2 diabetes, is a major health concern, particularly in Western societies. An understanding of the biological processes and mechanisms that promote obesity in childhood and adulthood is therefore imperative for the development of strategies for prevention and intervention. Although genetic and adult lifestyle factors are known to contribute to obesity, recent epidemiological, clinical and experimental studies suggest that the nutritional environment during the prenatal period may have important consequences on metabolic energy regulatory systems in later life (Barker \& Osmond 1986, Ravelli et al. 1999, Vickers et al. 2000).

Much of our current knowledge of the importance of prenatal nutrition has been derived from animal studies. In the rodent, the impact of maternal nutrition has been shown to induce long-term effects on behavioural, anthropometric and metabolic functions (Freinkel 1980, Lucas 1991). Since the developing fetus is sensitive to environmental conditions that modulate ontogenic pathways, it is thought the maternal metabolic consequences of prenatal undernutrition may modify the developing neural systems that control energy homeostasis in the fetus (Levin 2000).

Leptin plays a key role in energy homeostasis and acts on discrete neuroendocrine pathways within the hypothalamus to reduce food intake and body fat content (Mercer et al. 1996, Elmquist et al. 1998b). Leptin is secreted mainly from adipose tissue and acts both in the brain and in the peripheral tissues. Five alternatively spliced forms of the leptin receptor are produced (OBRa-e), of which only OBRb has a long cytoplasmic region that is required for signal transduction. Moreover, evidence is accumulating to suggest that obesity is associated with central leptin resistance (Flier 2004). For this reason, investigations over the past decade have focused on determining the mechanisms involved in the action of leptin on hypothalamic neural circuitry systems involved in energy homeostasis.

Key targets of leptin action are the orexigenic neurons within the hypothalamic arcuate nucleus that co-express the 
peptides neuropeptide Y (NPY) and agouti-related protein (AgRP), an antagonist of the melanocortin (MC) peptides at the MC-3 and -4 receptors (MC3/4R) (Cowley et al. 2001). These neurons express OBRb (Mercer et al. 1996, Elmquist et al. 1998a) and are inhibited by leptin. When leptin or its receptor levels (OBRb) are deficient, AgRP levels are elevated five- to tenfold in obesity (Ollmann et al. 1997, Shutter et al. 1997). NPY, the most potent orexigenic peptide, is elevated in response to reduced levels of leptin (Kalra et al. 1999) and produces hyperphagia, weight gain and the endocrine/metabolic characteristics of obesity (Heinrichs et al. 1998).

Another group of leptin-responsive neurons within the arcuate nucleus are the anorexigenic pro-opiomelanocortin (POMC) neurons, which also express leptin receptors, but in contrast to NPY/AgRP neurons, are stimulated by leptin (Cowley et al. 2001). These POMC neurons produce several neuropeptides derived from the POMC-polypeptide precursor, adrenocorticotrophin, $\beta$-endorphin, as well as the MCs $\alpha$-, $\beta$ - and $\gamma$-melanocyte-stimulating hormone (MSH), which are ligands for the MC3/4R (Vergoni et al. 1986, Yaswen et al. 1999, Kask et al. 2000).

In relation to our present investigation, previous studies have shown alterations in NPY neurons in weanling and adult offspring of gestational diabetic rat dams, and in weanling offspring of perinatal low-protein fed rat dams (Plagemann et al. 1999, 2000). Recent research in fetal mice of proteinrestricted rat dams during pregnancy, has also shown alterations in mRNA levels for the appetite regulatory peptides (POMC, NPY and AgRP) and the leptin receptor isoforms (Terroni et al. 2005), lending support to the hypothesis that changes in the nutritional status of the pregnant mother can alter the offspring's neuroendocrine system. However, the long-term consequences of maternal undernutrition during pregnancy on neuroendocrine gene expression in adult offspring are currently unknown, particularly when a nutrient-rich condition of high caloric density is encountered postnatally.

We have previously shown in rats that maternal undernutrition during gestation leads to increased adiposity and high circulating leptin and insulin concentrations in adult offspring (Vickers et al. 2000). Furthermore, combining prenatal undernutrition with postnatal high-fat nutrition exacerbated obesity development and further amplified hyperleptinaemia and hyperinsulinaemia. The aim of the present study was, therefore, to assess whether increased susceptibility to diet-induced obesity in offspring of undernourished mothers is related to alterations in neuroendocrine gene expression involved in the regulation of energy homeostasis.

\section{Materials and Methods}

The present study utilised a well-characterised model of maternal undernutrition in the rat (Vickers et al. 2005).
In brief, virgin Wistar rats (aged $100 \pm 5$ days) were time mated using a rat oestrous cycle monitor to assess the stage of oestrous of female animals prior to introducing the male. Following confirmation of mating by the presence of spermatozoa in a vaginal lavage, each dam was housed individually in standard cages containing wood shavings as bedding and free access to water. All rats were housed in the same room with a constant temperature maintained at $25{ }^{\circ} \mathrm{C}$ and a $12 \mathrm{~h}$ light: $12 \mathrm{~h}$ darkness cycle. Dams were randomly assigned to one of two nutritional groups, fed either ad libitum (AD) or were undernourished at $30 \%$ of AD intake (UN) of a standard rat chow diet, throughout gestation. After birth, pups were weighed and litter size was adjusted to eight pups per litter to assure adequate and standardised nutrition until weaning. Pups from undernourished mothers were crossfostered onto dams that had received AD feeding throughout pregnancy. From weaning, female offspring were fed either a standard chow (ADC $n=8$, UNC $n=8$ ) or a high-fat diet $(45 \% \mathrm{kcal}$ as fat; ADHF $n=8$, UNHF $n=8)$ ad libitum for the remainder of the study. At 24 weeks of age, body composition was assessed using dual energy X-ray absorptiometry (DEXA). Following an overnight food withdrawal, animals were euthanised by decapitation under halothane anaesthesia. Truncal blood was immediately collected into heparinised vacutainers stored on ice $\left(4^{\circ} \mathrm{C}\right)$, centrifuged and plasma collected for analysis. Whole rat brains were rapidly removed and placed on dry ice for slow freezing. Using a previously chilled rat brain matrix and consistent landmarks, one sagittal cut was made rostral to the optic chiasma and another sagittal cut was made rostral to the pons to produce three-thirds of whole brain, with the middle-third encasing the entire hypothalamic region. Tissues were then stored at $-80{ }^{\circ} \mathrm{C}$ until analysis. All procedures were approved by the Animal Ethics Committee of the University of Auckland.

Hypothalamic blocks encasing the regions of the arcuate, paraventricular, dorso- and ventromedial nuclei were isolated from the frozen dissected middle-third of whole brain, using appropriate co-ordinates of dissection (Bregma levels -1.3 to $-4.3 \mathrm{~mm}$; Paxinos \& Watson 1986).

Total RNA was isolated from half of each homogenised rat hypothalami using Trizol/chloroform extraction as directed by the manufacturer's instructions (Invitrogen). RNA was purified using the Qiagen midi column purification kit (Qiagen), quantified by nanodrop meter and assessed for integrity using the RNA 6000 Nano Labchip (Agilent Technologies, Santa Clara, CA, USA). TaqMan real-time PCR (qRT-PCR) was performed for each sample using the ABI PRISM 7900HT Sequence Detection System (PerkinElmer Applied Biosystems, Foster City, CA, USA). The PCRs were one cycle at $50{ }^{\circ} \mathrm{C}$ for $2 \mathrm{~min}$ and $95^{\circ} \mathrm{C}$ for $10 \mathrm{~min}$. The amplification was followed by 40 cycles of denaturation at $95^{\circ} \mathrm{C}$ for $15 \mathrm{~s}$ and annealing at $60^{\circ} \mathrm{C}$ for $1 \mathrm{~min}$. TaqMan gene expression assays and standard reagents (Applied Biosystems) were used for qRT-PCR of each sample for POMC (Assay ID: Rn00595020_m1), NPY (Assay ID: Rn00561681_m1), OBRb (Assay ID: Rn00561465_m1) and 18S rRNA 
(endogenous control). Oligonucleotides and TaqMan probe were designed for AgRP using the ABI Prism Primer Express (v. 2.0) software (Applied Biosystems) based on published sequences obtained from the GenBank database (GenBank accession number AF206017; forward: 5'-TTCCCAGAGTTCTCAGGTCTAAGTC-3'; reverse: 5'-GGATCTAGCACCTCTGCCAAA- $3^{\prime}$ and TaqMan probe: $5^{\prime}$-FAM-AAGAAGACAGCAGCAGAC- $3^{\prime}$ ). Standard curves were prepared for POMC, NPY, AgRP, OBRb and the endogenous control $18 \mathrm{~S}$ rRNA. For each experimental sample, the relative concentrations of each gene and endogenous control were determined from the appropriate standard curve. The quantification of gene expression for each experimental sample was then obtained by normalising the relative concentration of each gene to the amount of endogenous control.

\section{Statistical analyses}

All data are expressed as means \pm s.E.M. ( $n=8$ per group). The data were transformed to satisfy the criteria of ANOVA as follows: POMC was square root transformed, whereas OBRb, leptin and insulin data were log transformed. Analyses were conducted using the SigmaStat v. 3.1 statistical package (Jandel Scientific, San Rafael, CA, USA). Differences between groups were determined by two-way factorial ANOVA (prenatal undernutrition and postnatal high-fat diet as factors), followed by Bonferroni post hoc analysis. For those differences where the $F$-value was statistically significant, Bonferroni protected $t$-tests were used to search, post hoc for the significant differences between means within the specific groups. Statistical significance was accepted at $P<0 \cdot 05$.

\section{Results}

Prenatal undernutrition had no effect on hypothalamic POMC gene expression in chow-fed UN offspring when compared with AD offspring. However, UN offspring fed a high-fat diet postnatally had increased POMC expression when compared with $\mathrm{AD}$ high-fat-fed animals $(P<0 \cdot 05$, $t=3 \cdot 080$; Fig. 1). High-fat nutrition resulted in a significant increase in POMC expression $(P<0 \cdot 05, t=3.733)$ in $\mathrm{UN}$ offspring, but postnatal diet had no effect on $\mathrm{AD}$ offspring gene expression. There was a significant interaction between prenatal undernutrition and postnatal high-fat nutrition on increased POMC expression in UNHF offspring $(P<0 \cdot 01$, $F=10 \cdot 020$ ).

Similarly, there was no difference in NPY mRNA expression between UN and AD chow-fed offspring with prenatal undernutrition. In offspring exposed to prenatal undernutrition and fed the high-fat diet postnatally, NPY expression was increased when compared with ADHF offspring $(P<0 \cdot 05, t=3 \cdot 193$; Fig. 2$)$. In $\mathrm{UN}$ but not $\mathrm{AD}$

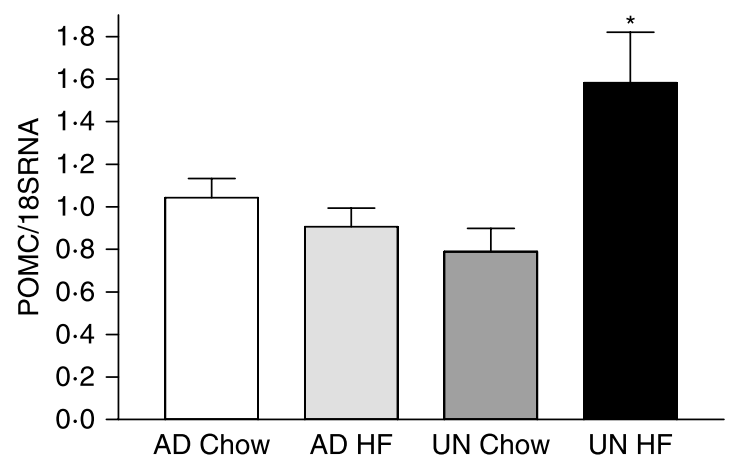

Figure 1 POMC mRNA expression relative to $18 \mathrm{~S}$ rRNA (arbitrary units) in AD or UN animals fed either a chow or a high-fat (HF) diet postnatally. *Significant versus all other groups. AD/UN $\times$ diet interaction $P<0 \cdot 01$. Data are means \pm s.E.M., $n=8$ per group.

offspring, NPY expression was significantly increased with high-fat nutrition when compared with UN offspring on chow diet $(P<0 \cdot 05, t=3 \cdot 184)$. As observed with POMC, there was also a significant interaction between prenatal undernutrition and postnatal high-fat diet on increased NPY expression in UNHF offspring $(P<0 \cdot 05, F=5 \cdot 332)$.

AgRP gene expression was significantly reduced by exposure to prenatal undernutrition in chow-fed offspring $(P<0 \cdot 05, t=2 \cdot 058$; Fig. 3$)$. In offspring exposed to prenatal undernutrition and fed the high-fat diet postnatally, AgRP expression was decreased when compared with ADHF offspring $(P<0 \cdot 05, t=2 \cdot 058)$. High-fat nutrition had no significant effect on AgRP mRNA expression in either UN or $\mathrm{AD}$ offspring, although there was a trend toward lower AgRP mRNA levels in both ADHF and UNHF offspring when compared with chow-fed controls.

OBRb mRNA expression was not significantly different between $\mathrm{AD}$ and UN offspring fed either the standard chow or the high-fat diet. However, high-fat nutrition in UN offspring resulted in a significant increase in OBRb expression $(P<0 \cdot 05, t=2 \cdot 704$; Fig. 4$)$, but was without effect on $\mathrm{AD}$ offspring expression. There was a significant

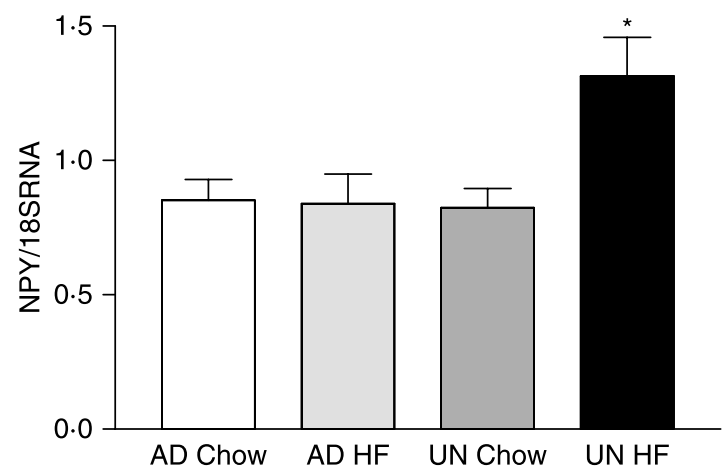

Figure 2 NPY mRNA expression relative to $18 \mathrm{~S}$ rRNA (arbitrary units) in AD or UN animals fed either a chow or a high-fat (HF) diet postnatally. *Significant versus all other groups. AD/UN $\times$ postnatal diet interaction $P<0 \cdot 05$. Data are means \pm S.E.M., $n=8$ per group. 


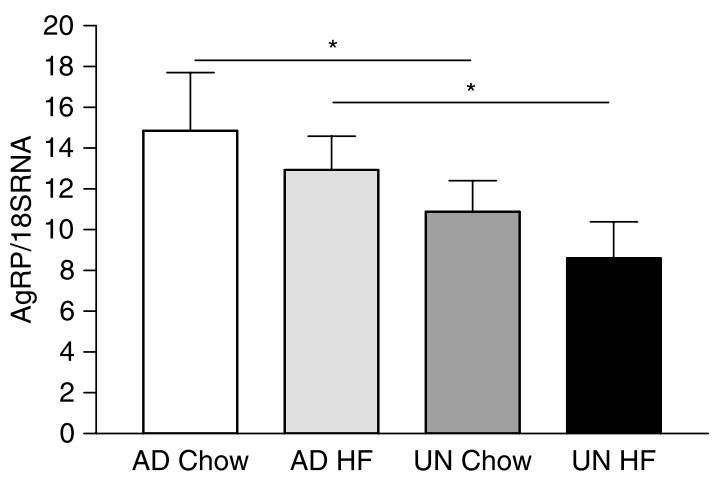

Figure 3 AgRP mRNA expression relative to $18 \mathrm{~S}$ rRNA (arbitrary units) in AD or UN animals fed either a chow or a high-fat (HF) diet postnatally. ${ }^{*} P<0 \cdot 05$. Data are means \pm s.E.M., $n=8$ per group.

interaction between prenatal undernutrition and postnatal high-fat diet on increased $\mathrm{OBRb}$ expression in UNHF offspring $(P<0 \cdot 05, F=5 \cdot 419)$.

Plasma leptin $(P<0 \cdot 01, t=4 \cdot 386)$ and insulin concentrations $(P<0 \cdot 01, t=4 \cdot 894)$ were significantly different by prenatal undernutrition in $\mathrm{UN}$ when compared with $\mathrm{AD}$ offspring fed postnatal high-fat nutrition, but not fed chow nutrition (Table 1). There was a significant interaction between prenatal undernutrition and high-fat diet on increased plasma leptin $(P<0.01, F=8.585)$ and increased plasma insulin concentrations $(P<0 \cdot 01, F=11 \cdot 949)$ in UNHF offspring. With high-fat nutrition, there was a significant increase in plasma leptin concentrations in both AD $(P<0 \cdot 05, t=4 \cdot 220)$ and $\mathrm{UN}(P<0 \cdot 05, t=8 \cdot 364)$ groups. Furthermore, within UN $(P<0 \cdot 05, t=5 \cdot 904)$ groups only, was there a significant increase in plasma insulin concentrations with high-fat nutrition.

Total fat mass (Table 1) was not significantly different between UNC and ADC offspring, but was significantly increased in UNHF when compared with ADHF offspring $(P<0 \cdot 05, t=4 \cdot 791)$. In both $\mathrm{AD}(P<0 \cdot 05, t=3 \cdot 347)$ and

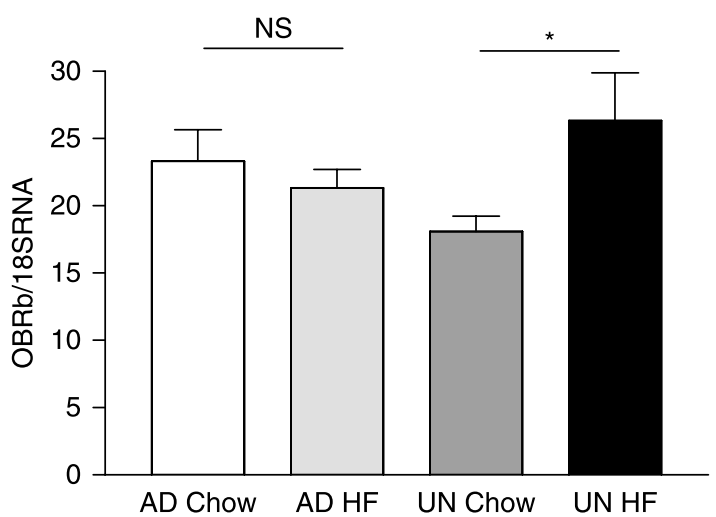

Figure $4 \mathrm{OBRb}$ mRNA expression relative to $18 \mathrm{~S}$ rRNA (arbitrary units) in $A D$ or UN animals fed either a chow or a high-fat (HF) diet postnatally. ${ }^{*} P<0 \cdot 05$. AD/UN $\times$ postnatal diet interaction $P<0 \cdot 05$. Data are means \pm S.E.M., $n=8$ per group. NS, not significant.
UN $(P<0 \cdot 05, t=8 \cdot 510)$ groups, high-fat nutrition resulted in a significant increase in fat mass. There was a significant interaction between prenatal undernutrition and high-fat diet on increased fat mass in UNHF offspring $(P<0 \cdot 01$, $F=13 \cdot 327)$.

Caloric intake (Table 1) was increased by prenatal undernutrition in UN when compared with AD offspring fed either a standard chow diet $(P<0 \cdot 05, t=2 \cdot 944)$ or a highfat diet $(P<0 \cdot 05, t=2 \cdot 944)$. High-fat nutrition had no effect on caloric intake in both $\mathrm{AD}$ and $\mathrm{UN}$ animals.

\section{Discussion}

The hypothalamic neuropeptide network plays a key role in the regulation of energy homeostasis. Furthermore, it has been suggested that early nutritional influences may impact on the normal development and maturation of this neuroendocrine network for the organism's immediate survival (Levin 2000). Yet, these early alterations may have no future adaptive value if a different postnatal environment is encountered (Gluckman \& Hanson 2004), resulting in an increased susceptibility to developing obesity. It is known from previous rodent studies using models of gestational diabetic dams, gestational protein-deprived and perinatal protein-deprived dams that changes in the early (prenatal and neonatal) nutritional status of the pregnant mother can alter the offspring's neural system at fetal, weanling and adult age (Plagemann et al. 1999, 2000, Terroni et al. 2005). However, to date, no studies have been undertaken to investigate the consequences of gestational maternal undernutrition on the offspring's neural system.

Using a well-established rodent model of maternal undernutrition (Vickers et al. 2005), the present study investigated in adult female offspring the effects of and interactions between prenatal maternal undernutrition and postnatal high-fat diet on hypothalamic POMC, NPY, AgRP and $\mathrm{OBRb}$ gene expression and susceptibility to obesity development. We were unable to quantitate POMC, NPY, $\mathrm{AgRP}$ and $\mathrm{OBRb}$ protein expression by western blot analysis, since the immunoreactive signals were very weak and below the level of detection.

We have shown that based on prenatal influences alone, UNC offspring did not develop an obese phenotype, even though they demonstrate a small, but significant increase in food intake. Circulating leptin and insulin levels remained unchanged, and there were no significant differences in POMC, NPY and OBRb mRNA expression, but there was a significant downregulation in AgRP mRNA expression.

Furthermore, we have been able to demonstrate that based on prenatal influences within offspring fed postnatal high-fat nutrition (UNHF versus ADHF), UNHF offspring develop significant increases in both fat mass and food intake, as well as an increase in circulating plasma levels of both leptin and insulin. With respect to mRNA expression, this is accompanied by increases in both POMC and NPY, a decrease in 
Table 1 Comparison of fasting plasma leptin and insulin levels, per cent total body fat dual energy X-ray absorptiometry (DEXA) and caloric intake (calories consumed per day per gram body weight). Data are means \pm s.E.M., $n=8$ per group

\begin{tabular}{|c|c|c|c|c|}
\hline & Leptin (ng/ml) & Insulin (ng/ml) & Total fat mass $(\%)$ & $\begin{array}{l}\text { Caloric intake } \\
\text { (kcal/g body weight) }\end{array}$ \\
\hline AD chow & $11 \cdot 08 \pm 1 \cdot 46$ & $0 \cdot 28 \pm 0 \cdot 04$ & $31 \cdot 59 \pm 2 \cdot 53$ & $0 \cdot 180 \pm 0 \cdot 01$ \\
\hline AD high fat & $30 \cdot 00 \pm 4.93$ & $0.37 \pm 0.06$ & $41.73 \pm 1.94$ & $0 \cdot 192 \pm 0 \cdot 02$ \\
\hline UN chow & $11 \cdot 38 \pm 1 \cdot 05$ & $0 \cdot 26 \pm 0.02$ & $30 \cdot 46 \pm 1 \cdot 18$ & $0 \cdot 203 \pm 0 \cdot 01$ \\
\hline UN high fat & $83.50 \pm 18.90$ & $2 \cdot 25 \pm 0.92$ & $56 \cdot 24 \pm 2 \cdot 61$ & $0 \cdot 215 \pm 0.03$ \\
\hline Prenatal effect & NS & NS & NS & $P<0.05$ \\
\hline Postnatal diet effect & $P<0.05$ & $P<0.05$ & $P<0.05$ & NS \\
\hline Interaction & $P<0.01$ & $P<0.01$ & $P<0.05$ & NS \\
\hline
\end{tabular}

NS, not significant.

AgRP, but no significant change in OBRb. Interestingly, with postnatal high-fat feeding ADHF offspring did not show any significant differences in POMC, NPY, AgRP and OBRb expression or caloric intake. However, they showed a significant increase in total fat mass and circulating plasma levels of both leptin and insulin. Postnatal high-fat nutrition induced a significant increase in POMC, NPY and OBRb expression, but no change in AgRP expression in UNHF offspring. Furthermore, these offspring developed a significant increase in circulating plasma levels of both leptin and insulin and a significant increase in total fat mass without any change in caloric intake.

According to the predictive adaptive response hypothesis, a developing organism adjusts its physiology to be appropriate for its predicted mature environmental range, such that a mismatch between the developmental and the adult environment may lead to an increased risk of disease development (Gluckman \& Hanson 2004). Our data support this theory and suggest that changes in energy regulatory systems of the hypothalamus may be key pathways that modify susceptibility to obesity development.

Our present findings also suggest that exposure to prenatal undernutrition results in adult dysregulation of appetite homeostasis and reduced AgRP mRNA expression, possibly via central leptin resistance, which we have previously shown can occur in the absence of obesity and hyperleptinaemia and is associated with increased plasma C-peptide and triglyceride levels (Krechowec et al. 2006). We have also demonstrated that, while exposure to prenatal undernutrition can increase food intake, the development of amplified obesity characterised by excessive fat mass accrual requires a critical interaction with postnatal high-fat nutrition.

In diet-induced obesity, AD and UN offspring fed postnatal high-fat nutrition have increased fat mass in association with hyperleptinaemia and hyperinsulinaemia, with no change in food intake. This suggests that exposure to high-fat nutrition determines susceptibility to obesity development, via mechanisms independent of increased food intake. Decreased transport of leptin into the brain has been suggested as one mechanism causing central leptin resistance in diet-induced obesity (Van Heek et al. 1997, Banks et al. 1999). However, central leptin gene therapy fails to overcome leptin resistance in diet-induced obesity (Wilsey et al. 2003), suggesting downstream signalling defects as possible primary causes of leptin resistance. In the present study, we were unable to detect changes in POMC, NPY, AgRP and OBRb mRNA expression in ADHF offspring, as reported previously (Harrold et al. 1999, Wang et al. 2002). The mechanisms contributing to diet-induced obesity in this study may therefore be primarily metabolic in nature, involving stimulation of fat synthesis, a reduction in activity level (Vickers et al. 2003), fat oxidation, energy expenditure and thermogenesis. Moreover, the possible interplay of other hypothalamic neuropeptides, which function independently of leptin, such as melanin-concentrating hormone, and also galanin and the orexins, which are highly responsive to dietary fat (Leibowitz \& Wortley 2004) may have contributed a role in mediating the metabolic mechanisms of diet-induced obesity in AD and UN offspring.

The concurrent hyperleptinaemic and hyperinsulinaemic levels with increased fat accrual in diet-induced obese $\mathrm{AD}$ and UN offspring may represent the failure of leptin's metabolic action in normally inhibiting insulin secretion in pancreatic $\beta$-cells (Kieffer et al. 1997, Seufert et al. 1999). This may have subsequently produced the anabolic effect of de novo lipogenesis (Kieffer \& Habener 2000) and further promotion of adipogenesis in diet-induced obese $\mathrm{AD}$ and $\mathrm{UN}$ offspring. This positive feedback loop of leptin resistance and compensatory hyperinsulinism results in dysregulation of the adipoinsular axis (Vickers et al. 2001) and suggests leptin resistance at the level of the pancreas (Breier et al. 2001) in diet-induced obese AD and UN offspring.

The failure of hyperleptinaemia to regulate NPY mRNA levels in UNHF offspring in the present study suggests that NPY neurons are less sensitive to leptin's suppressive effects (NPY neuronal resistance). Alternatively, the increase in NPY expression may be the result of inhibited leptin signalling, at the level of reduced signal transducer and activator of transcription-3 (STAT-3) activation, and involving increased expression of suppressor of cytokine signalling-3 (SOCS-3), an inhibitor of leptin signalling (Munzberg et al. 2004). Our observation of increased NPY expression, as previously 
reported (Gao et al. 2002, Huang et al. 2004) may function to attenuate catabolic signalling.

Despite increased hyperleptinaemic levels enhancing POMC expression in UNHF offspring, excessive fat mass accrual was not restricted in UNHF offspring resulting in amplification of obesity. Increased POMC mRNA levels have been reported in other diet-induced obesity studies (Ziotopoulou et al. 2000, Torri et al. 2002). However, it is difficult to interpret changes in POMC mRNA, since $\alpha-\mathrm{MSH}$ and $\beta$-endorphin have opposing catabolic and anabolic effects on energy homeostasis respectively (Kalra et al. 1999). However, it is possible that increased $\beta$-endorphin production either as a result of increased POMC expression or by the stimulatory effect of increased NPY expression in UNHF offspring (Horvath et al. 1992, Kalra et al. 1995) led to a potentiation in its hypothalamic transmission. The resulting outcome is attenuation in catabolic signalling by decreasing sympathetic activity and produced the anabolic effect of increased fat deposition (Leibowitz \& Wortley 2004).

The increased expression of OBRb in obese UNHF offspring is not surprising, since POMC and NPY expression are increased and $\mathrm{OBRb}$ is co-localised in both these neuronal populations (Elias et al. 1999, Lin et al. 2000). However, in spite of increased OBRb expression in transducing the satiety effects of hyperleptinaemic signalling by normally decreasing orexigenic peptides, NPY expression was increased in UNHF offspring. As mentioned previously, this could possibly be mediated at the level of reduced STAT-3 activation, and involve increased expression of SOCS-3, an inhibitor of leptin signalling (Munzberg et al. 2004), resulting in an attenuation of catabolic signalling. UNHF offspring also showed increased POMC expression suggesting the possibility of an increase in responsiveness of POMC neurons to hyperleptinaemic signalling mediated by increased OBRb. However, the differential effects of increased production of $\alpha-\mathrm{MSH}$ and $\beta$-endorphin by increased POMC may also contribute to the attenuation of catabolic signalling.

In conclusion, our findings suggest that mismatched early developmental and mature environments determine a higher susceptibility to obesity development through alterations in POMC, NPY, AgRP and OBRb gene expression with hyperleptinaemia and hyperinsulinaemia, which may be associated with both central and peripheral leptin resistance. In addition, our study provides genetic evidence in keeping with the predictive adaptive response theory. Further studies are required to delineate the underlying cellular mechanisms of the prenatal influences on susceptibility to diet-induced obesity within specific regions of the brain.

\section{Acknowledgements}

This work was supported by the National Research Centre for Growth and Development (NRCGD) and the Health Research Council (HRC) of New Zealand. BAI-T was a recipient of postgraduate scholarships from the $\mathrm{HRC}$ and the
National Heart Foundation of New Zealand. The authors also thank Ms Alice Coveny for her assistance with the animal studies and laboratory analysis. The authors declare that there is no conflict of interest that would prejudice the impartiality of this scientific work.

\section{References}

Banks WA, DiPalma CR \& Farrell CL 1999 Impaired transport of leptin across the blood-brain barrier in obesity. Peptides 20 1341-1345.

Barker DJP \& Osmond C 1986 Infant mortality, childhood nutrition and ischaemic heart disease in England and Wales. Lancet 1 1077-1081.

Breier BH, Vickers MH, Ikenasio BA, Chan KY \& Wong WP 2001 Fetal programming of appetite and obesity. Molecular and Cellular Endocrinology $18573-79$.

Cowley MA, Smart JL, Rubinstein M, Cerdan MG, Diano S, Horvath TL, Cone RD \& Low MJ 2001 Leptin activates anorexigenic POMC neurons through a neural network in the arcuate nucleus. Nature $\mathbf{4 1 1}$ $480-484$

Elias CF, Aschkenasi C, Lee C, Kelly J, Ahima RS, Bjorbaek C, Flier JS, Saper CB \& Elmquist JK 1999 Leptin differentially regulates NPY and POMC neurons projecting to the lateral hypothalamic area. Neuron $\mathbf{2 3}$ 775-786.

Elmquist JK, Bjorbaek C, Ahima RS, Flier JS \& Saper CB 1998a Distributions of leptin receptor mRNA isoforms in the rat brain. Journal of Comparative Neurology 395 535-547.

Elmquist JK, Ahima RS, Elias CF, Flier JS \& Saper CB 1998b Leptin activates distinct projections from the dorsomedial and ventromedial hypothalamic nuclei. PNAS 95 741-746.

Flier JS 2004 Obesity wars: molecular progress confronts an expanding epidemic. Cell 116 337-350.

Freinkel N 1980 Banting Lecture 1980. Of pregnancy and progeny. Diabetes 29 1023-1035.

Gao J, Ghibaudi L, van Heek M \& Hwa JJ 2002 Characterization of dietinduced obese rats that develop obesity after 6 months of high-fat followed by 1 month of low-fat diet. Brain Research 936 87-90.

Gluckman PD \& Hanson MA 2004 Living with the past: evolution, development, and patterns of disease. Science 305 1733-1736.

Harrold JA, Williams G \& Widdowson PS 1999 Changes in hypothalamic agouti-related protein (AGRP), but not alpha-MSH or pro-opiomelanocortin concentrations in dietary-obese and food-restricted rats. Biochemical and Biophysical Research Communications 258 574-577.

Heinrichs SC, Menzaghi F \& Koob GF 1998 Neuropeptide Y-induced feeding and its control. Vitamins and Hormones 54 51-66.

Horvath TL, Naftolin F, Kalra SP \& Leranth C 1992 Neuropeptide-Y innervation of beta-endorphin-containing cells in the rat mediobasal hypothalamus: a light and electron microscopic double immunostaining analysis. Endocrinology 131 2461-2467.

Huang XF, Xin X, McLennan P \& Storlien L 2004 Role of fat amount and type in ameliorating diet-induced obesity: insights at the level of hypothalamic arcuate nucleus leptin receptor, neuropeptide $\mathrm{Y}$ and proopiomelanocortin mRNA expression. Diabetes, Obesity and Metabolism 6 35-44.

Kalra PS, Norlin M \& Kalra SP 1995 Neuropeptide Y stimulates betaendorphin release in the basal hypothalamus: role of gonadal steroids. Brain Research 705 353-356.

Kalra SP, Dube MG, Pu S, Xu B, Horvath TL \& Kalra PS 1999 Interacting appetite-regulating pathways in the hypothalamic regulation of body weight. Endocrinology Reviews 20 68-100.

Kask A, Rago L, Wikberg JE \& Schioth HB 2000 Differential effects of melanocortin peptides on ingestive behaviour in rats: evidence against the involvement of $\mathrm{MC}(3)$ receptor in the regulation of food intake. Neuroscience Letters 283 1-4.

Kieffer TJ \& Habener JF 2000 The adipoinsular axis: effects of leptin on pancreatic beta-cells. American Journal of Physiology 278 E1-E14.

www.endocrinology-journals.org 
Kieffer TJ, Heller RS, Leech CA, Holz GG \& Habener JF 1997 Leptin suppression of insulin secretion by the activation of ATP-sensitive $\mathrm{K}+$ channels in pancreatic beta-cells. Diabetes 46 1087-1093.

Krechowec SO, Vickers M, Gertler A \& Breier BH 2006 Prenatal influences on leptin sensitivity and susceptibility to diet-induced obesity. Journal of Endocrinology 189 355-363.

Leibowitz SF \& Wortley KE 2004 Hypothalamic control of energy balance: different peptides, different functions. Peptides 25 473-504.

Levin BE 2000 The obesity epidemic: metabolic imprinting on genetically susceptible neural circuits. Obesity Research 8 342-347.

Lin S, Storlien LH \& Huang X-F 2000 Leptin receptor, NPY, POMC mRNA expression in the diet-induced obese mouse brain. Brain Research 875 89-95.

Lucas A 1991 Programming by early nutrition in man. Ciba Foundation Symposium 156 38-50.

Mercer JG, Hoggard N, Williams LM, Lawrence CB, Hannah LT \& Trayhurn P 1996 Localization of leptin receptor mRNA and the long form splice variant (Ob-Rb) in mouse hypothalamus and adjacent brain regions by in situ hybridization. FEBS Letters 387 113-116.

Munzberg H, Flier JS \& Bjorbaek C 2004 Region-specific leptin resistance within the hypothalamus of diet-induced obese mice. Endocrinology 145 4880-4889.

Ollmann MM, Wilson BD, Yang Y-K, Kerns JA, Chen Y, Gantz I \& Barsh GS 1997 Antagonism of central melanocortin receptors in vitro and in vivo by agouti-related protein. Science 278 135-138

Paxinos G \& Watson C 1986 The Rat Brain in Stereotaxic Coordinates. 2nd edn, Australia: Academic Press.

Plagemann A, Harder T, Melchior K, Rake A, Rohde W \& Dorner G 1999 Elevation of hypothalamic neuropeptide Y-neurons in adult offspring of diabetic mother rats. Neuroreport 10 3211-3216.

Plagemann A, Harder T, Rake A, Melchior K, Rohde W \& Dorner G 2000 Hypothalamic nuclei are malformed in weanling offspring of low protein malnourished rat dams. Journal of Nutrition 130 2582-2589.

Ravelli ACJ, van der Meulen JHP, Osmond C, Barker DJP \& Bleker OP 1999 Obesity at the age of $50 \mathrm{y}$ in men and women exposed to famine prenatally. American Journal of Clinical Nutrition 70 811-816.

Seufert J, Kieffer TJ, Leech CA, Holz GG, Moritz W, Ricordi C \& Habener JF 1999 Leptin suppression of insulin secretion and gene expression in human pancreatic islets: implications for the development of adipogenic diabetes mellitus. Journal of Clinical Endocrinology and Metabolism 84 670-676.

Shutter JR, Graham M, Kinsey AC, Scully S, Luthy R \& Stark KL 1997 Hypothalamic expression of ART, a novel gene related to agouti, is up-regulated in obese and diabetic mutant mice. Genes and Development 11 593-602.

Terroni PL, Anthony FW, Hanson MA \& Cagampang FR 2005 Expression of agouti-related peptide, neuropeptide $\mathrm{Y}$, pro-opiomelanocortin and the leptin receptor isoforms in fetal mouse brain from pregnant dams on a protein-restricted diet. Brain Research Molecular Brain Research 140 111-115.
Torri C, Pedrazzi P, Leo G, Muller EE, Cocchi D, Agnati LF \& Zoli M 2002 Diet-induced changes in hypothalamic pro-opio-melanocortin mRNA in the rat hypothalamus. Peptides 23 1063-1068.

Van Heek M, Compton DS, France CF, Tedesco RP, Fawzi AB, Graziano MP, Sybertz EJ, Strader CD \& Davis HR Jr 1997 Diet-induced obese mice develop peripheral, but not central, resistance to leptin. Journal of Clinical Investigation 99 385-390.

Vergoni AV, Poggioli R \& Bertolini A 1986 Corticotropin inhibits food intake in rats. Neuropeptides 7 153-158.

Vickers MH, Breier BH, Cutfield WS, Hofman PL \& Gluckman PD 2000 Fetal origins of hyperphagia, obesity and hypertension and its postnatal amplification by hypercaloric nutrition. American Journal of Physiology 279 E83-E87.

Vickers MH, Reddy S, Ikenasio BA \& Breier BH 2001 Dysregulation of the adipoinsular axis - a mechanism for the pathogenesis of hyperleptinemia and adipogenic diabetes induced by fetal programming. Journal of Endocrinology 170 323-332.

Vickers MH, Breier BH, McCarthy D \& Gluckman PD 2003 Sedentary behavior during postnatal life is determined by the prenatal environment and exacerbated by postnatal hypercaloric nutrition. American Journal of Physiology, Regulatory, Integrative and Comparative Physiology 285 R271-R273.

Vickers MH, Gluckman PD, Coveny AH, Hofman PL, Cutfield WS, Gertler A, Breier BH \& Harris M 2005 Neonatal leptin treatment reverses developmental programming. Endocrinology 146 4211-4216.

Wang H, Storlien LH \& Huang XF 2002 Effects of dietary fat types on body fatness, leptin, and ARC leptin receptor, NPY, and AgRP mRNA expression. American Journal of Physiology, Endocrinology and Metabolism 282 E1352-E1359.

Wilsey J, Zolotukhin S, Prima V \& Scarpace PJ 2003 Central leptin gene therapy fails to overcome leptin resistance associated with diet-induced obesity. American Journal of Physiology, Regulatory, Integrative and Comparative Physiology 285 R1011-R1020.

Yaswen L, Diehl N, Brennan MB \& Hochgeschwender U 1999 Obesity in the mouse model of pro-opiomelanocortin deficiency responds to peripheral melanocortin. Nature Medicine 5 1066-1070.

Ziotopoulou M, Mantzoros CS, Hileman SM \& Flier JS 2000 Differential expression of hypothalamic neuropeptides in the early phase of dietinduced obesity in mice. American Journal of Physiology, Endocrinology and Metabolism 279 E838-E845.

Received in final form 18 January 2007

Accepted 24 January 2007

Made available online as an Accepted Preprint 26 January 2007 